\title{
THE SEVEN-STEP MODEL FOR E-GROCERY FULFILMENT
}

\author{
Martin Barnett and Paul Alexander \\ School of Management Information Systems, Edith Cowan Universit, Perth WA, Australia
}

\begin{abstract}
Online grocery shopping is a specialised subset of online shopping with difficulties all of its own. Most of these occur, not at the front end of customer ordering, but during the last mile: the home delivery process. A study of third party fulfilment in Australia has demonstrated the existence of an optimal seven-step model for linking the lowest possible delivery costs to a given customer density. Developed from a national case example, our model shows that as volume of deliveries increases, cost characteristics and activities fall within seven clearly bounded stages as business volumes increase. Where competition is centred around this component of grocery sales, e-grocers wishing to compete using a cost leadership strategy are likely to reduce their prices (to customers) to such levels. However, a survey of Australian e-Grocers indicates that some may be immune to this pressure, and therefore continue to pocket very significant profits derived frome-fulfilment.
\end{abstract}

Key words: e-Groceries, e-fulfilment, logistics, online retail, delivery, transport, marketing, last mile

\section{INTRODUCTION}

Business-to-consumer e-commerce stimulates fierce debate at all levels: from angel investors, through practitioners, to the earnest inhabitants of business schools and readers of IS journals. Nowhere are the battle lines between sceptics and believers in the retail revolution more definitely drawn than on the battlefield of e-grocery.

Online ordering complemented by home delivery for the grocery sector is perceived as particularly problematic. Compared with most other goods of- 
fered online, groceries have lower value to bulk ratios, present greater handling problems and have low margins.

Despite this the potential for interactive home grocery shopping attracts attention on two counts. Firstly, a significant proportion of household spending in developed countries goes through relatively few retail grocery stores, and secondly, a successful approach to this retail area serves as a model for other retail areas to follow suit. To date clear and accepted business models for success have yet to emerge.

Some studies conducted on the economics associated with online retailing fulfilment, take a macro and perhaps simplistic view of the situation. Evident in these cases is a tacit assumption that simple relationships exist between costs and volume/density of fulfilment, and that these hold during both commencement and routine operation of the business. This paper describes the costs associated with delivery services for a general fulfilment organisation attempting to address different customer densities, and demonstrates that for different densities and volumes, businesses need to be on different steps of a predictable cost model operate optimally.

e-Grocery operations provide a bellwether for Internet fulfilment operations in all fields. They are an extreme and sensitive system owing to their high bulk, perishability, high frequency and low intrinsic per-unit value, combined with customer expectations of delivery urgency, stringent and challenging timetabling, routing, storage, picking and packing methods, and health issues. This separates them from other online retailers focused on other consumer durables. In these lines, the above fulfilment factors may be mitigated by other aspects of the value proposition, and consequently greater versatility consequence.

In other words, the overall value of the purchase is not particularly high, hence the delivery cost may form a significant portion. This in turn makes the customer potentially sensitive to delivery prices.

Some studies have been conducted on the economics associated with etailing fulfilment in general (Schuster and Sporn 1998; Laseter, Houston et al.; Laseter, Houston et al.) and for e-grocers in particular, but these take a macro view. Their main simplification is a tacit assumption that simple linear relationships exist between costs and volume/density of deliveries. This paper reports on the costs associated with delivery services for a third-party fulfilment organisation (ie. not a specialist e-grocer), as it scaled its operations to meet increasing delivery volumes and different customer densities, and suggests that for different densities and volumes, one operates on different steps of a seven-step cost model.

We use as an example, this model applied to an Australian city of known density and grocery consumption. Its concentrated suburban spread makes this example readily applicable to other European cities, and local data may 
be input to yield area-specific predictions. On the basis of this, e-grocery businesses operating in Australia are examined to predict the viability of such operations.

\section{RETAILING AND E-GROCERY MARKETS}

Home shopping, particularly Internet shopping, is on the increase. For example, research group IMRG reports that online shopping in the UK grew 19 times faster than high street shopping in 2002, and doubled in value during the first six months of 2003 (to $£ 4.75$ billion). In 2003 this continued as Internet shopping reached an all-time high in the UK in November - soaring $44 \%$ at an annual growth rate 12 times higher than the $3.6 \%$ reported for all retail sales by the British Retail Consortium. (Netimperative). These figures are particularly important for us as the UK has led the way in the development of grocery supply chain efficiency and Tesco is the most successful online grocer to date (Tesco Annual Report).

By any standards these increases are substantial, and they mean that more product than ever before is being sent to people's houses in vans. A similar growth rate is reported for the US by Forrester Research, which says firsthalf results for 2003 were worth about $£ 61$ billion compared with $£ 45$ billion the previous year. In 2005 , US $\$ 118$ billion worth of U.S. online retail spending will result in 2 billion deliveries, according to Jupiter Media Metrix, mainly by third party carriers (UPS, Federal Express and the U.S. Postal Service being major examples).

The retail grocery trade in developed countries has profound social and economic impact on the whole of society. It accounts for 30 to $50 \%$ of all retail spending on physical products, depending on income levels and definitions (Wileman and Jary 1997). As each person in a cash-based economy buys food, this puts retail grocers in a market class of their own. It has given rise to sophisticated networks of supermarket chains expanding by virtue of their advantages of economy of scale, buying power, brand marketing and cross marketing with loyalty and group promotion packages.

The emergence of larger retail operators has enabled the use of more efficient methods of distribution. Over time, wholesalers have more or less disappeared from many of the retail markets, with large retailers dealing directly with manufacturers. This trend has probably been greatest in the grocery retail market; between 1982 and 1992, retail turnover increased by 125 per cent whilst turnover from delivered wholesale trade increased by only 59 per cent.

The method of delivery has also changed enormously as retailers become more efficient. Before the emergence of multiple retailers, manufacturers or 
wholesalers made most deliveries to retailers. Such deliveries were of an assortment of products to individual retail outlets. Nowadays, manufacturers tend to deliver large amounts of a particular product in each delivery to a retailer's own centralised warehouse. The retailer has effectively internalised the wholesaling and much of the transportation function. Centralised warehousing leads to reduced stock levels, reduced delivery visits per store, reduction of necessary storage space in stores themselves, fewer incidents of running out of stocks and empty shelves in the outlet, and lower shrinkage rates.

\section{FULFILMENT AND E-GROCERS}

When delivering physical goods there are three key delivery and logistics drivers to business sustainability. These are sales concentration (the value of sales per square kilometre), population density and total population (Laseter, Houston et al.).

Population density and sales concentration set upper limits on revenue expectations for aspiring e-grocers; and based on the low overall population size and density, modest ones in most parts of Australia except perhaps Melbourne and Sydney. But the costs of delivering must also be considered in relation to this density.

There are many factors any e-grocer must consider in moving its online orders that last mile. The actual solution is set by the nature of the product and the customer expectations inherent in the business model for the egrocer - speed required, range of deliveries, conditions of delivery, bundled services (eg. COD, signature on delivery, etc). These factors greatly affect the costs, and can significantly impact the overall profitability of the operator; indeed its very survival (Harty 2000; Bannister 2001; Colin 2001; Hoyt 2001; Mendelson 2001; Griffith 2002).

The e-grocery delivery model is extreme. It is driven by customer expectations, health regulations, and perishability factors, picking stringency issues, varying storage requirements of product, traditional alternatives, and potentially high delivery overheads (table 1).

\begin{tabular}{|l|l|}
\hline Item & Notes \\
\hline 4-temperature vehicle & \$200K capital cost + increased running costs \\
\hline Complex pick \& pack & Many items, temperature variation \\
\hline $\begin{array}{l}\text { Same-day delivery require- } \\
\text { ment }\end{array}$ & Customer expectations \\
\hline Intelligent picking & Quality of produce, knowledge of fruit/veg, expiry dates \\
\hline
\end{tabular}

Table 1: Typical fulfilment requirements for an e-grocer 
There is certainly no shortage of information on these aspects (eg. (Barsh, Crawford et al. 2000)), but for the most part they are associated with particular business models at a particular point in time (or with a particular goal). This has lead to the appearance of a plethora of fulfilment models, each of which can be successful in one situation and yet fail in another (Reynolds 2000; Colin 2001). But is it possible that these different models may be different aspects of the same one; each aspect being appropriate for a different phase of the business's operation, and the type of operation itself? Tacit in many explanations of delivery models is that any particular delivery model for an e-grocer is scalable for all densities and any customer volume. Evidence presented in this paper suggests this is not so. There are in fact, several discrete alternatives for delivery, which become appropriate for different volume and density conditions.

\section{EVIDENCE OF A DEVELOPING COST INFRA- STRUCTURE FROMA START-UPFULFILMENT ORGANISATION}

Data provided by a third-party fulfilment operator, a large Australian National organisation (ANO) forms the basis for this model (ANO 2003). ANO is a long-established fulfilment, logistics, delivery and courier business which facilities other businesses as an alliance partner. It is uniquely placed to provide insight into costing and fulfilment processes for diverse industries.

\section{Relevance of ANO's experience}

ANO presented an unusual opportunity to study emerging fulfilment processes for several reasons.

a) Its large size, significant market share, high customer profile and welldeveloped sales/marketing/promotions infrastructure, and overall brand power, which allowed rapid acceptance of the services being offered.

b) The long term profit focus which reduced the pressures on achieving quick-hit successes at the expense of long term success strategies.

c) Rapid mobilisation due to an existing logistics capability, which allowed leverage across the whole delivery, pick/pack, cross-dock, and warehousing range of services.

d) ANO had the ability to change organisational structures/sizes rapidly in line with needs, through redeployment and secondment of key resources.

e) Significant budget was available to implement and acquire necessary resources. 
f) Ongoing financial analysis was available, to assist with recommending new structures, infrastructures, capabilities and pricing/costing models.

\section{The business goals}

ANO sought to capitalise on existing infrastructure and profile to establish a presence in the emerging online retailer market as an extension to existing fulfilment that represented its core market. It recognised that online retailing will, not only attract new customers but also absorbing some from others. This led to the recognition that it needed to attract a share of this emerging channel to protect its existing market share.

ANO wanted to differentiate itself by being an early-entrant provider of specialist capabilities tailored for e-fulfilment.

\section{The startup strategy}

In developing a specific online retailing fulfilment service, ANO adopted an underpinning strategy of using existing capabilities to provide the service to rapidly turn "on" or "off" (from an e-fulfilment perspective) any delivery, logistics, warehouse, pick \& pack, courier or regular delivery service at very short notice, with little barriers to setting up, and with few capital costs. This approach was taken to allow a dynamic e-fulfilment organisation to be piloted in the face of unpredictable market demand Additionally, the organisation took a strategic view of building this business, concentrating initially on developing accurate, cost-effective internal capabilities and attracting external markets rather than chasing early profits.

As the market becomes firm, ANO is building appropriate separate, bigger-scale but less dynamic, infrastructures, and attention is switching to profit.

To determine the most appropriate resources and capabilities at any point in the organisation's development of this business, analyses were undertaken which quantified:

- Direct per unit costs to deliver a particular capability;

- Basic resource availability from existing functions;

- Leverage through economies of scale (by combining e-fulfilment and existing fulfilment service volumes);

- Costs to scale up existing functions (rather than setting them up specifically);

- Fixed costs.

These analyses were undertaken prior to initiating the project as a whole, using projected market data. As this data firmed, and as the service grew from its inception, the analyses were repeated regularly and if necessary, a different approach was constructed at each step. The catalyst for this step was a combination of - changes in customer volume, customer density and/or resource capability/availability. Because the e-fulfilment service was 
sold quite discretely from other services, it was possible to monitor customer activity and continuously build a picture of alternative and optimal solutions based on these parameters.

\section{Delivery Approach}

Services offered to business customers included picking up from their premises, and delivery to another specified metropolitan location within 4 5 business hours. Thus, a morning pick-up would be delivered the same afternoon, while an afternoon delivery would be delivered the following morning. This schedule applied to a clearly defined region. Some (outer) parts of the metropolitan area were specifically excluded because of the low density of businesses. Any deliveries required outside the time or area constraints would be delivered by special means using ad hoc arrangements. These were "one-off situations undertaken to support customer-service. Most customers were regular subscribers to the service, all with a standard pick-up point, but often multiple drop-off points.

Pickups and deliveries were undertaken (by contractors) in business hours. The delivery region was divided into four delivery "runs" (figure 1). Each run was a roughly defined "spoke", using a warehouse/loading bay as a common "hub". This was calculated as being the minimum to provide delivery guarantees (time and range) that had been set. A single delivery contractor would eventually service each of these runs. Though discrete, the actual route of the "run" varied each day depended on the exact address of both pickups and deliveries. Contractors utilised vans and planned their routes so all pickups and deliveries could be transacted with maximum efficiency.

Thus, contractors had a roughly fixed route which had to be navigated in a fixed time,

This structure imposed eventual maxima on the number of pickups and deliveries that could be undertaken by a single contractor. The actual number of deliveries was governed by transporting issues such as traffic conditions, parking availability, locating obscure addresses, and also the speed of the actual pickup and delivery process, itself a function of any added services (eg. obtaining a signature, collecting cash). 


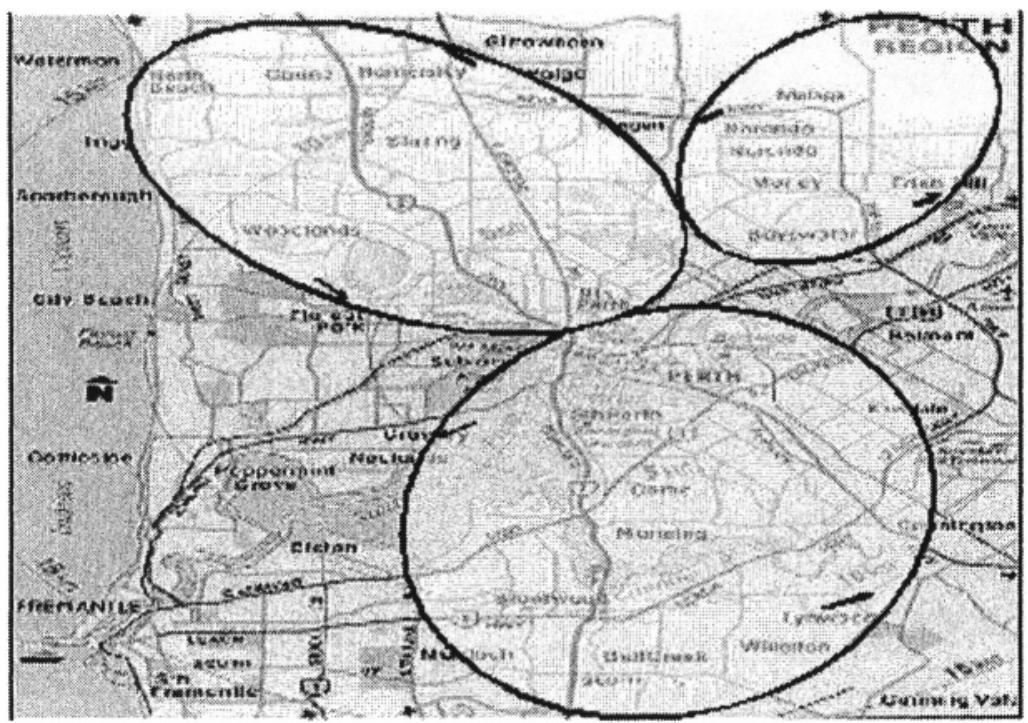

Figure 1. Structure of delivery routes

\section{THE PHASES}

Figure 2 shows the average parcel cost for given daily delivery volumes, calculated frequently, based on fixed and variable costs at any particular time. Whenever volume of deliveries increased, the costs were recalculated.

As can be seen, economies of scale appeared. However analysis revealed that the cost trend is not a linear or even a stepwise reduction of cost (often seen in cost verses volume plots), but consists of various different segments.

Seven discrete steps in evolving e-fulfilment capabilities were observed. At the time of completion of the observations, ANO had passed through three of them, and had identified and was preparing for the next stages.

We defined each step as "requiring a restructure of relevant business processes to adapt to evolving volume and cost conditions". So doing, at each phase ANO identified resource requirements, payment methods, and associated infrastructure requirements.

It also developed a Spreadsheet model to calculate cost and volume relationships for the particular phase being operated in. This model then served to monitor financial performance of the project. The mathematics for each phase was not complex but involved several variables - and different ones for each phase. 


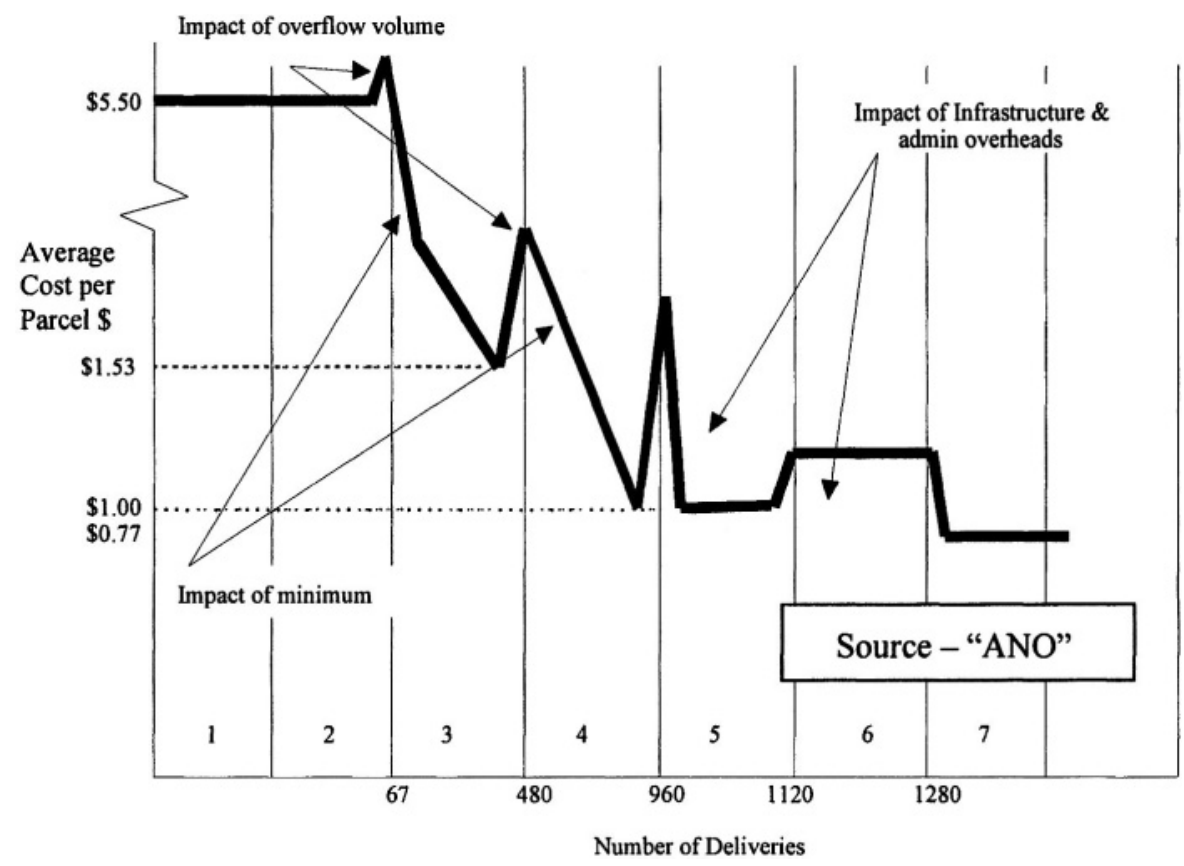

Figure 2: Cost characteristics of fulfilment implementation, showing approximate volume breaks.

It is valuable to include the mathematics here as it serves to explain the underlying driving mechanism.

\section{Phase 1: Ad hoc delivery}

As the first e-fulfilment orders were received, they were delivered via couriers, and by special arrangement with staff. Few systems and no cost or performance contracts were in place. Cost of delivery was dictated by normal courier/delivery costs and fixed at around $\$ 5.00$ per delivery and less than $20 \mathrm{Kg}$.

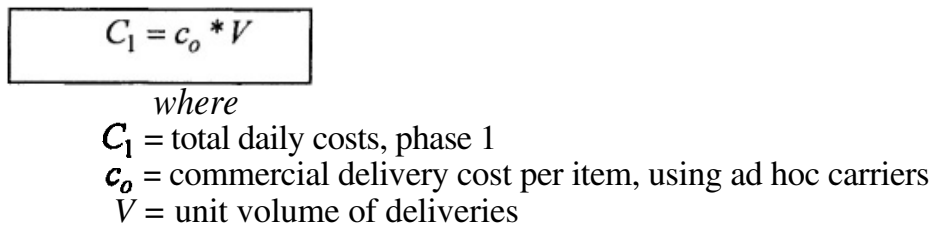

\section{Phase 2: Low volume outsourced arms length arrangements}

As a steady flow of orders built up, arrangements were made with contract service providers. The deliveries were pooled into regular contract services. Taxis were used when the other services were full or did not meet promised delivery timelines. 
$C_{2}=\left(c_{s}^{*} V_{s}\right)+\left(c_{o}^{*} V_{o}\right)$

where

$C_{2}=$ total daily costs, phase 2

$c_{s}=$ commercial delivery cost per item, standard items

$c_{0}=$ commercial delivery cost per item, overflow items

$V_{s}=$ unit volume of deliveries, standard items

$V_{o}=$ unit volume of deliveries, overflow items

\section{Phase 3: Startup of defined delivery "runs"}

When sufficient volumes justified it, basic routes were put into place, though they were not yet evolved into the 4 spokes of the final delivery pattern. These were based on a definable delivery run. They were resourced by contractors with their own general-purpose vehicles, who were offered a fixed daily fee. Thus, this phase built on the previous phase. Ad hoc (taxi) services were still used to meet specific overflow demands.

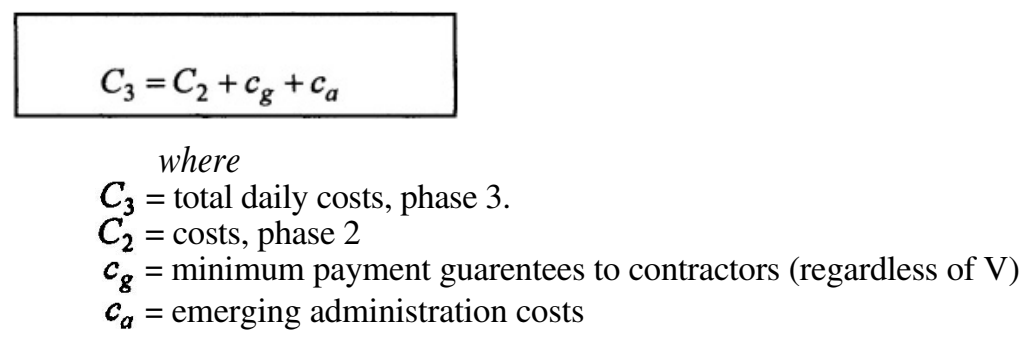

\section{Phase 4: Minimum Regional delivery runs with high-percentage re- gional coverage \& low capital investment strategy}

As volumes grew, the initial rounds were expanded and multiplied to provide delivery to guaranteed standards throughout a region. This required 4 rounds - the spokes.

During this period, minimum payment guarantees were still in place for delivery contractors. There was considerable attention placed on process efficiency, and aligning capabilities with customer promises during this phase. Also, all deliveries were handled by contractors, thus precluding the use of overflow or ad hoc services. 


$$
C_{4}=\left(c_{s}^{*} n_{s}\right)+C_{\mathrm{a} 2}
$$

where

$C_{4}=$ total daily costs, phase 4

$\mathbf{c}_{\mathbf{s}}=$ fixed daily costs per spoke

$n_{s}=$ number of spokes

$C_{\mathrm{a} 2}=$ increasing administration costs

\section{Phase 5: Sophisticated regional delivery runs}

As rounds began to fill, further analysis (now with significant numbers of transactions and substantial trend information) was undertaken to re-align and refine delivery rounds.

Particular attention was paid to parcel size (volume and weight), number of parcels per delivery and per round (ie. density of deliveries). Also during this period the intention (this phase has not yet occurred) is to reduce minimum payment guarantees and negotiate longer-term contracts at per-parcel rates reflecting higher volume and overall contractor revenue expectations.

Importantly, the building of a purpose-built infrastructure will begin. This calls for cross-dock, and loading/unloading facilities, management and administration staff.

$$
C_{5}=\left(c_{s 2} * V_{s}\right)+C_{\text {admin }}+C_{a s s e t s}
$$

where

$C_{5}=$ total daily costs, phase 5

$C_{\text {admin }}=$ increased administration $\&$ booking costs

$C_{\text {assets }}=$ costs of maintaining assets

$c_{s 2}=$ commercial delivery cost per item, renegotiated contracts

$V_{s}=$ unit volume of deliveries, standard items

\section{Phase 6: Growing regional delivery runs}

As volumes increase, analysis by ANO indicates that emphasis should be placed on efficiently filling existing delivery runs and scaling up volume. Where one contractor had serviced each round, multiple contractors on some rounds will be required. Extra flexibility and cost effectiveness in deliveries will be the result.

Additionally, contractor payment emphasis will be shifted, from a "perparcel" to a "per-delivery" basis, to better position the service for accepting business-to-business assignments, where multiple deliveries to single sites is expected. 
$C_{6}=C_{5}+C_{2}$

where

$C_{6}=$ total daily costs, phase 6

$C_{5}=$ total daily costs, phase 5

$C_{2}=$ total daily costs, phase 2

\section{Phase 7: Range-increasing capabilities}

Once the operation was proven the major pressure was created by the potential to increase market; primarily based on offering similar services over a wider geographic range.

Analysis indicated this would be best accomplished through:

- alliances with other fulfilment/delivery services;

- joining of other regional e-fulfilment groups being set up in other states.

Financial implications have not been analysed for this stage, but ANO's analysts consider its approach to be to focus on more complex (sophisticated) administration structures, and online systems to automate and integrate processes. Economies of scale, and increased market penetration for national customers are seen as the main drivers to reach this stage.

The physical characteristics of these phases are summarised in Table 2

\begin{tabular}{|c|c|c|c|c|c|c|c|}
\hline \multirow[t]{2}{*}{ Cost Item } & \multicolumn{7}{|c|}{ Phases } \\
\hline & 1 & 2 & 3 & 4 & 5 & 6 & 7 \\
\hline Ad hoc component (courier) & • & e & - & & & & \\
\hline $\begin{array}{l}\text { Inhouse arms length contrac- } \\
\text { tor }\end{array}$ & & - & & & & & \\
\hline $\begin{array}{l}\text { Guaranteed minimum vol- } \\
\text { umes }\end{array}$ & & & - & ๑ & & & \\
\hline $\begin{array}{l}\text { Committed in-house contrac- } \\
\text { tors }\end{array}$ & & & - & - & - & - & \\
\hline $\begin{array}{l}\text { Significant overflow ex- } \\
\text { pected }\end{array}$ & & & & • & - & & \\
\hline Significant administration & & & & - & - & - & - \\
\hline $\begin{array}{l}\text { Infrastructure (x-dock, sys- } \\
\text { tems, etc) }\end{array}$ & & & & & & ๑ & - \\
\hline $\begin{array}{l}\text { Specialised in-house contrac- } \\
\text { tors }\end{array}$ & & & & & & & - \\
\hline Alliances & & & & & & & - \\
\hline
\end{tabular}

Table 2: Summary of features in each step 


\section{TRIGGERING THE STEPS}

The model shows distinct phases, each with different cost and logistical characteristics. But these phases are not merely a recognition of these differences. They appear to be actively "triggered" by factors directly related to delivery volume.

Thus, each phase appears to be triggered by volume overload condition existing in the previous phase. This results in a rapidly increasing percentage of deliveries overflowing into a backup, high-cost service, and gives rise to a changed break-even cost structure that soon justifies increased resources required for the next phase.

Why this is so uncovers a fundamentally important aspect of e-fulfilment infrastructures: For any particular logistical, organisational and financial configuration of the service, there is a minimum and a maximum sustainable volume.

Another feature evident in this case is that the unit delivery cost is not optimal until the phase is almost completed. This is a function of overheads that are required to establish each stage. In the early stages, these take the form of minimum guarantees for contractors, but eventually include major infrastructure projects and administrative structures.

A phase appears to be cost-optimised just before overflow conditions increase unit costs and trigger the next phase.

\section{IMPLICATIONS FOR NEW E-FULFILMENT OP- ERATIONS}

ANO offers a rare insight into start-up delivery cost dynamics. The most appropriate costing, resourcing, service offerings, and infrastructure development is determined, then immediately implemented.

It is unlikely that all these stages can be shown to occur in other efulfilment start-up businesses. It is more likely that management determines a model, which then works sub-optimally until a break-even, or target volume/service level/service region is reached.

In other words, we contend that this case demonstrates a "best case" cost behaviour model, and that the costs it suggests will be the lowest that can be expected for a similarly resourced operation servicing (comparable to the Australian metropolitan) client base. In addition, since the structure and resourcing is quite orthodox, this we believe, has wide applicability to start-up e-fulfilment operations. 


\section{PRELIMINARY EVIDENCE ON PRICING STRUCTURES FOR AUSTRALIAN E-GROCERS}

A short display of typical delivery charges for e-grocers in Australian cities is shown in Table 3. Based on discussions with ANO executives and research in progress into 40 Australian e-grocers, we believe this model is at work in most fulfilment operations.

ANO sees the logistics and fulfilment industry as a straightforward one, with relatively few fundamental methods of delivering the service. Warehouses, transport operations, courier operations and the like are operated similarly by competitors in the industry. Competitive advantage is occasionally achieved by a radical change to processes or services, but much more often by slight advantages in cost efficiencies, ability to leverage existing delivery networks and warehouses. Many industry costs are similar between competitors, set by local rental prices, award wage rates, and marketvalue courier (and other) resources; all shared by all competitors in a region. Supporting this scenario are the closely aligned prices and absence of raw discounting ${ }^{29}$ that exists in the industry.

Our model describes costs in terms of these basic components, and so we consider it reasonable to apply it to the e-grocers' deliveries; at least at a macro level that can distinguish between, say, phase 1 and phase 3 operations. The only added complication for e-grocers appears to be the need to deal with perishability issues, which demand the use of special "4temperature" delivery vehicles (that is, they carry product at frozen, chilled, room and oven temperature). Such vehicles cost approximately A $\$ 200,000$, so place an immediate overhead cost on operations that must be factored into any cost calculations. Though we do not make these calculations in this paper, we observe (in table 3 ) that delivery charges for Australian e-grocers are often broken into separate charges for dry goods (without issues of perishability), and for perishables. We believe this reflects the differences in economics and infrastructure at work.

The study indicates also that the major Australian e-grocery suppliers are fulfilling at prices that cover even phase 1 costs, and apparently at a profitable level. (A more detailed examination of this data is under preparation for a forthcoming paper submitted to Bled 2004)

${ }^{29}$ But there is fierce competition nevertheless, and also much opportunity for discounting based on marginal prices charged for spare capacity - for example, of a truck delivering to a particular location. 
That this is sustainable is indicated by the stability of these services, which have not been subjected to significant change in 3 years, and all players surveyed have been in existence for (at least) that length of time.

\begin{tabular}{|c|c|c|c|}
\hline Supplier & $\begin{array}{l}\text { Cities } \\
{ }^{*}=\text { some areas }\end{array}$ & $\begin{array}{l}\text { Delivery Charge } \\
\text { (\$A) }\end{array}$ & $\begin{array}{l}\text { Delivery Charge (A\$), Cur- } \\
\text { rent (from web site) }\end{array}$ \\
\hline $\begin{array}{l}\text { Woolworths } \\
\text { (Homeshop) }\end{array}$ & Syd *, Canb, Melb & $\begin{array}{l}\$ 12.50(\min \text { order } \\
\$ 60)\end{array}$ & $\$ 12.50(\min$ of $\$ 30)$ \\
\hline Coles & Syd *, Melb * & $\begin{array}{l}\$ 13.69(\min \text { order } \\
\$ 60)\end{array}$ & $\begin{array}{l}\$ 12.50 \text { (2hr window), } \$ 9.95 \\
\text { (4hr window), no min or- } \\
\text { ders-Syd, } \$ 9.95(2 \mathrm{hr}) / \$ 7.95 \\
\text { (4hr) Melb. Different prod- } \\
\text { uct prices to normal grocery } \\
\text { lines. }\end{array}$ \\
\hline Greengrocer & $\begin{array}{l}\text { Syd, Melb, some } \\
\text { regions }\end{array}$ & $\begin{array}{l}\$ 4.00 \text { refrig ( } \mathrm{min} \\
\text { order } \$ 25)\end{array}$ & $\begin{array}{l}\text { (Now through Woolworths) } \\
\text { System under restructure } \\
\text { following takeover }\end{array}$ \\
\hline Shopfast & $\begin{array}{l}\text { Syd - metro, cen- } \\
\text { tral coast \& Woo- } \\
\text { longong }\end{array}$ & $\$ 6.55$, no $\min$ order & $\begin{array}{l}\$ 5.95 \text { to } \$ 10.95 \text { depending } \\
\text { on delivery time slot }\end{array}$ \\
\hline Dewsons & Perth * & NA & $\begin{array}{l}\$ 6.93+6 \% \text { (full delivery) } \\
6 \% \text { pickup } \\
\$ 6.93 \text { delivery only }\end{array}$ \\
\hline Electrolley & Perth & NA & $\begin{array}{l}\$ 5.95 \text { (unrefrigerated) for } \\
\text { selected items more than } \\
\$ 30 \text { per order, } \$ 13.65 \text { oth- } \\
\text { erwise. For refrigerated, } \\
\$ 75 \text { min. Min overall or- } \\
\text { der }=\$ 30\end{array}$ \\
\hline
\end{tabular}

Table 3: Delivery charges for significant Australian e-grocers (NineMSN 2003)

\section{CONCLUSIONS \& DIRECTIONS FOR FURTHER RESEARCH}

The ANO case provides valuable insights into the dynamics of providing an e-fulfilment capability for online retailers. It supports the very strong relationship between customer density and cost of the "last mile" so often quoted by authors (Laseter and al; Laseter, Houston et al.). However, where there is an implied assumption that this relationship is somehow linear, or at least a continuous function based on static forces, ANO shows that several quite discrete phases occur as the operation responds to demand pressures. 
The immediacy of response, and the readiness to adjust to needs without too much short-term sensitivity to cost (ANO was/is aiming at positioning for a dominant operation, so sees this as a pilot and, to some extent, an "experimental platform") is unusual in a business. More often, such organisations may not have the capabilities, resources, and/or the will to adapt and divert them.

But this does not mean that ANO's response and approach to e-fulfilment is different from other organisations. On the contrary, the services it is building are entirely orthodox. Indeed, the value of this study is that it provides transferable insight relevant to many other organisations.

Underpinning this, we believe there are four major drivers:

- the need to respond to immediate customer demand;

- the need to maintain this response at the lowest cost;

- the need to prepare for response to the next phase of anticipated customer demand, and;

- the desire to minimise risk at any point;

This creates a response pattern that consists of discrete steps which represent the organisation's need to establish structures and capabilities that last long enough to serve their purpose (to meet customer needs at the lowest cost), yet provide a relative degree of stability of processes and resources (to be manageable and practical). At each point, the organisation establishes the least-risk path of meeting these needs, which (in ANO's case) means making most use of direct cost options while delaying implementation of capital costs until trends indicate reduced risk.

Cost efficiency demands for deliveries, in turn, have lead to a push for maximum units of delivery to saturate a particular delivery run. This translates to a lower per-unit cost as volume increases. But saturation of the runs carries with it costs in the form of expensive overflow delivery processes. As this is not a cost efficient approach, it then serves as a catalyst to create a newer, more appropriate and cost efficient structure. However, once created, its (new) capabilities are underused, so driving up the per-unit delivery cost again.

Complicating this situation is the difference in cost dynamics in each phase. It is not just a matter of scaling particular costs up or down, and having the money in the bank to cover the situation. Costs are controlled by making decisions about how resources are allocated, and how payments are made to delivery resources. In different phases, it is necessary to switch from per-hour payments (to ensure availability of contractors) to per unit payments (to ensure minimisation of per unit costs) to per-delivery payments (to maximise potential revenue on a delivery run).

As volume increases, various administration and infrastructure tasks become significant and must be addressed. These are not as reversible as some 
of the contractor-related decisions. Building a cross-dock facility for instance, is an investment that is not easily reversed and must be justified by activity projections that are both favourable and reliable.

The ANO case also shows that there appears to be an appropriate response to delivery volumes, and with it a characteristic set of cost dynamics, and with those a minimum attainable per-unit delivery cost. We believe the services that ANO is building are driven directly by customer demands. This organisation's response is not radical, and we would expect similar approaches on providing these services from other industry entrants. The equations developed in this paper therefore can be transferred to other organisations.

We note that some organisations, particularly those extending from offline to online operations, will telescope some of the steps together, for instance delaying the establishment of committed delivery resources. How they approach this will depend on the competition for reducing delivery price. Some customers may be insensitive to delivery price, for instance where there are few delivery alternatives or where the delivery price is only a small percentage of the price of the item being delivered. Where this occurs, it is possible to maintain the convenience of an ad hoc service.

However, where large grocers require a third party e-fulfilment service provider, we believe this model will operate.

For such organisations, we expect the phase transitions to continue until a continuously scalable operation has been reached. In the ANO case, this may represent a situation we would call Phase 8 . Such a phase would be characterised by low, and relatively constant per-unit costs. This goal provides a major driver for the creation of large, wide-distribution organisations and may indicate strong pressure to create a few dominant e-fulfilment providers in the future of this market.

Using this model, it should be possible to estimate minimum achievable costs for any volume of units delivered. How many units can be delivered is based on the total delivery potential and the density. Total delivery potential sets the maximum rate of units delivered in a time period, while the delivery density influences the costs of delivering those units. Thus, Figure 2 can be used as a guide to establishing achievable costs, while facilitating planning for projected activity.

For Australian conditions, it suggests that potential delivery costs can vary from around $\$ 5.50$ in phase 1 to under $\$ 0.75$ for phase 7 operations. Ironically, Australia is not a densely populated country, with only two cities (Melbourne and Sydney) with high population densities. So, whether these volumes can be achieved equally across the nation is debatable in the short term. Exploring this aspect provides a direction for current research. 
The material adduced shows that, despite fears that online ordering and home delivery would be a dead duck from the start, Australian e-grocers are delivering their goods and charging prices that allow them to completely cover the costs of a phase e-fulfilment model. Under these circumstances, it is certainly possible that these businesses are able to operate the e-fulfilment component of the business.

Integrating the data presented within Table 2 with that of Figure 2, we note that consumers are demonstrating willingness to pay the necessary additional cost for the selection of a home delivery channel

The limiting problems of scaling an interactive home shopping service do not necessarily arise from the "last mile" component. On the contrary, given reasonable urban density an increase in delivery volume enables dramatic reduction in cost-per-parcel.

The phased model indicates that to lower costs, competitive pressures have the potential to drive fulfilment operations associated with e-grocers to become more sophisticated in their operations - essentially driving them through stages two to six.

In terms of cost competition, margins for the groceries themselves are relatively lean, so we predict that when it comes, these battles will be fought on the delivery front, where there is still much fat. At potential least unit cost for a stage 6 operation, of around \$0.77, the current prices being charged, of $\$ 5.50+$ leave considerable room for downward pressures to impact delivery charges.

The ANO case describes the cost dynamics of a single startup fulfilment operation targeting e-businesses. In 2002, there were well over 40 e-grocers in Australia who must be using operations with similar characteristics (Ltd 2002), and many appear to have been in existence for 2 to 3 years, indicating some degree of stability in their pricing strategies and offerings. Almost all were offering customer deliveries integrated to their online product, and these deliveries were either performed as a function of the business or an outsourced supplier/partner. Without exception, delivery charges represented what we would call Phase 1 costs; that is, based on ad hoc delivery. We are interested in analysing the changing price structures as competition increases in such an environment. Indeed, there is some indication that the major bricks and mortar grocers are positioning to compete in the online channel, and the nature of their fulfilment operations and offerings will provide further insight into, and expansion of our model.

We note that net profit margins are not traditionally high in groceries (3\% to $6 \%$ are commonly recognised net returns), and with current e-grocery delivery charges, a significant profit stream may well exist that is at least as significant as the margins from the groceries themselves. Under such conditions, we speculate that competitive e-grocery offerings may well be based 
on the delivery price and characteristics rather than the groceries. This will in turn influence the very nature of the e-grocery industry, impacting the players, their delivery performance, and perhaps the viability of the industry. Analysing Australian e-grocers as they respond to increasing competition, will elucidate this.

Our study has also highlighted the strong connection between customer density and the potential for efficacy of last mile deliveries. With Australia's highly urbanised population based in relatively isolated cities of different densities we have an opportunity to further examine the dynamics of this model. Using it, we can make predictions about e-grocers' fulfilment offerings in different cities, and so test the operation of the model more fully. Papers are in progress focussing in on both these areas.

\section{REFERENCES}

ANO (2003) Personal correspondence and discussions supplied and held under conditions of corporate and client confidentiality to Paul Alexander

Bannister, C. (2001). "Shopping simply by site." Retail World 54(5): 16.

Barsh, J., B. Crawford, et al. (2000). "How e-tailing can rise from the ashes." McKinsey Quarterly(Number 3, 2000): 98-109.

Bos, G. (1999). Virtual Supermarket Index. 1999.

Colin, J. (2001). The impact of e-commerce on transport. Joint OECD/ECMT Seminar, Paris.

Griffith, V. (2002). "Welcome to Tesco, your "glocal" superstore." Strategy+Business (www.strategy-business.com)?(?): ?

Harty, C. (2000). “Australia Post wins Coles contract.” Retail World 53(23): 23.

Hogarth-Scott, S. and S. Parkinson (1994). "Barriers and stimuli to the use of information technology in retailing." International Review of Retail, Distribution and Consumer Research 4(3): 257-275.

Hoyt, D. (2001). “Tesco Delivers.” Graduate School of Business, Standford University Case Number: EC-32.

IMRG (2003). IMRG e-Retail Sales Data Survey. 2003.

Laseter, T. and e. al The last mile to somewhere. Strategy+Business: 1-5.

Laseter, T., P. Houston, et al. The last mile to nowhere. Strategy+Business: 40-48.

Laseter, T., P. Houston, et al. (2000). The last mile to nowhere:Flaws and fallacies in Internet home delivery schemes. Strategy+Business, Booz Allen Hamilton Inc. 2003: 40-48.

Laseter, T., P. Houston, et al. (2001). The last mile to somewhere. Strategy+Business, Booz Allen Hamilton Inc. 2003: 29-34.

London Economics (1997). Competition in retailing. London, Office of Fair Trading.

Ltd, P. A. G. P. (2002). Australian e-Grocers Page, Professional Assignments Group Pty Ltd.

Mendelson, H. (2001). "Webvan: The new and improved milkman." Graduate School of Business, Standford University Case Number: EC-31.

Murphy, D. (2001). "When speed is king." Far Eastern Economic Review 164(7): 36.

NineMSN (2003). NineMSN Fact sheet \& vendor sites, NineMSN.com. 2003.

Reynolds, J. (2000). "Supply chain, distribution and fulfilment." International Journal of Retail \& Distribution Management 28(10): 417-444. 
Schuster, A. and B. Sporn (1998). "Potential for online grocery shopping in the urban area of Vienna." Electronic Markets 8(2): 13-16.

Wileman and M. Jary (1997). Retail power plays: From trading to brand leadership. New York, Ney York University Press. 